University of Nebraska - Lincoln

DigitalCommons@University of Nebraska - Lincoln

USDA National Wildlife Research Center - Staff Publications
U.S. Department of Agriculture: Animal and Plant Health Inspection Service

2012

\title{
Integrity and Retention of Ear-Tag Radiotransmitters in Domestic Cattle and Feral Horses
}

Bryan M. Kluever

Utah State University, klueverb@gmail.com

Laura Lagos

University of Santiago de Compostela

Stewart W. Breck

USDA/APHIS/WS National Wildlife Research Center, stewart.w.breck@aphis.usda.gov

Larry D. Howery

University of Arizona, Ihowery@ag.arizona.edu

Manuel L. Sanmartín

University of Santiago de Compostela

See next page for additional authors

Follow this and additional works at: https://digitalcommons.unl.edu/icwdm_usdanwrc

Kluever, Bryan M.; Lagos, Laura; Breck, Stewart W.; Howery, Larry D.; Sanmartín, Manuel L.; Bergman, David L.; and Bárcena, Felipe, "Integrity and Retention of Ear-Tag Radiotransmitters in Domestic Cattle and Feral Horses" (2012). USDA National Wildlife Research Center - Staff Publications. 1156.

https://digitalcommons.unl.edu/icwdm_usdanwrc/1156

This Article is brought to you for free and open access by the U.S. Department of Agriculture: Animal and Plant Health Inspection Service at DigitalCommons@University of Nebraska - Lincoln. It has been accepted for inclusion in USDA National Wildlife Research Center - Staff Publications by an authorized administrator of DigitalCommons@University of Nebraska - Lincoln. 


\section{Authors}

Bryan M. Kluever, Laura Lagos, Stewart W. Breck, Larry D. Howery, Manuel L. Sanmartín, David L. Bergman, and Felipe Bárcena 
Tools and Technology

\title{
Integrity and Retention of Ear-Tag Radiotransmitters in Domestic Cattle and Feral Horses
}

\author{
BRYAN M. KLUEVER, ${ }^{1,2}$ School of Natural Resources and the Environment, University of Arizona, Tucson, AZ 85721, USA \\ LAURA LAGOS, Institute of Food Research and Analysis, University of Santiago de Compostela, Constantino Candeira $s / n$., \\ 15782 Santiago de Compostela, Spain \\ STEWART W. BRECK, United States Department of Agriculture, Animal and Plant Health Inspection Service, Wildlife Services, \\ National Wildlife Research Center, 4101 LaPorte Avenue, Fort Collins, CO 80521, USA \\ LARRY D. HOWERY, School of Natural Resources and the Environment, University of Arizona, Tucson, AZ 85721, USA \\ MANUEL L. SANMARTÍN, Institute of Food Research and Analysis, University of Santiago de Compostela, Constantino Candeira $s / n$., \\ 15782 Santiago de Compostela, Spain \\ DAVID L. BERGMAN, United States Department of Agriculture, Animal and Plant Health Inspection Service, Wildlife Services, \\ 8836 N 23rd Avenue, Suite 2, Phoenix, AZ 85021, USA \\ FELIPE BÁRCENA, Institute of Food Research and Analysis, University of Santiago de Compostela, Constantino Candeira s/n., \\ 15782 Santiago de Compostela, Spain
}

\begin{abstract}
Radiotelemetry is an important tool for wildlife management and research, but in some cases attachment of neck collars can be problematic. An alternative in large mammals is to attach transmitters to the ear, though little is published about ear-tag radiotransmitter integrity (i.e., how long a transmitter emits a useful signal) and retention (i.e., how long a transmitter remains attached to an animal). Here we report eartag transmitter integrity and retention from 2 studies monitoring free-ranging calves (Bos taurus) in eastern Arizona, USA, and feral horse (Equus ferus) foals in northwestern Spain. Transmitter integrity and retention was lower for transmitters attached to foals then calves. The primary cause for reduced integrity was antennas breaking off, whereas the primary retention problem involved transmitters ripping out of the ear. When data were pooled across study sites, mean integrity and retention loss was 111 days and 180 days, respectively. Transmitters attached to the interior of the outer ears had retention rates $>2$ times higher than transmitters attached to the exterior of the outer ear ( $88 \%$ vs. $43 \%)$. We recommend that researchers intending to utilize ear-tag transmitters for studies on large domestic or wild animals attach transmitters to the interior of the outer ear, reinforce transmitter antennas in order to improve integrity, and report integrity and retention rates. (C) 2012 The Wildlife Society.

This article is a U.S. government work, and is not subject to copyright in the United States.
\end{abstract}

KEY WORDS Arizona, Bos taurus, Equus caballus, predation, radiotelemetry, Spain.

The use of radiotelemetry in wildlife studies is commonplace and knowledge of ecological processes for many species has been enhanced as a result thereof (Millspaugh and Marzluff 2001, Morrison et al. 2008). For example, juvenile survival is critical to population dynamics (Gaillard et al. 1993, Kissling et al. 2009), and radiotelemetry has been employed to quantify juvenile survival in a variety of wild and domestic ungulates, such as roe deer (Capreolus capreolus; Aanes and Andersen 1996, Raganella-Pelliccioni et al. 2006), whitetailed deer (Odocoileus virginiaunus; Long et al. 1998), elk

Received: 6 February 2011; Accepted: 26 October 2011; Published: 4 January 2012

\footnotetext{
${ }^{1}$ E-mail: bmkluever@yahoo.com

${ }^{2}$ Present address: Utah State University, College of Natural Resources, Wildland Resources Department, 5230 Old Main Hill, Logan, UT 84322-5200, USA.
}

(Cervus canadensis; Smith and Anderson 1998, DeVivo et al. 2011), and cattle (Bos taurus; Oakleaf et al. 2003, Breck et al. 2011).

For terrestrial mammals, radiotransmitters typically are attached by placing a collar containing the transmitter around the neck of the animal, but there are situations where neck collars may not be appropriate or ideal. A common scenario where neck collars are problematic is when the individual's neck is expected to grow significantly in diameter during the study, and, therefore, result in the collar becoming too tight over time (e.g., juv ungulates or animals that gain neck girth during the breeding season; Decker et al. 1992, Smith et al. 1998, Diefenbach et al. 2003). Conventional and expandable neck radiocollars also may be inappropriate and/ or potentially hazardous to animals with fusiform bodies and tapered necks (Lancia 1979, Wheatley 1997, Arjo et al. 2008).

Ear-tag radiotransmitters (hereafter, ear-tag transmitters) solve some of these issues and have been used on several wild 
species, including elk (Barber-Meyer et al. 2008), whitetailed deer (Garrott et al. 1985), American beaver (Castor canadensis; Arjo et al. 2008), and wild boar (Sus scrofa; Fisher et al. 2004). They also have been used to monitor the movement, survival, behavior, and predation of juvenile cattle and feral horses (Equus ferus; Oakleaf et al. 2003, Kluever et al. 2008, Breck et al. 2011, L. Lagos and F. Bárcena, University of Santiago de Compostela, unpublished data). Despite the potential benefits of ear-tag transmitters, difficulties can arise due to problems associated with integrity (i.e., how long the transmitter emits a useful signal) and retention (i.e., how long the tag remains attached to the ear). Integrity can be problematic because, in an effort to keep the tags light, components may be less durable than those included in radiocollars. Retention also can be problematic because the mass of a radiotag can cause it to tear free due to fragility of animals' ears. Our objectives were to 1) report rates of ear-tag transmitter integrity and retention in bovine calves and feral horse foals, and 2) describe factors that may influence rates of integrity and retention. We then compare and contrast our results with the published literature and make recommendations regarding how retention and integrity of ear-tag transmitters can be improved.

\section{STUDY AREAS}

We monitored calves with ear-tag transmitters on the East Eagle (EE) grazing allotment in the Apache-Sitgreaves National Forest in eastern Arizona, USA $\left(32^{\circ} \mathrm{N}, 109^{\circ} \mathrm{W}\right)$. The EE encompassed approximately 30,000 ha, ranged in elevation from $1,500 \mathrm{~m}$ to $2,600 \mathrm{~m}$ above mean sea level, contained mostly steep and rugged topography, and ranged from thickly timbered areas to open meadows. Annual precipitation ranged from $20 \mathrm{~cm}$ to $40 \mathrm{~cm}$, and mean annual temperature was $15.5^{\circ} \mathrm{C}$, with extremes of $-6^{\circ} \mathrm{C}$ and $35^{\circ} \mathrm{C}$ (Desert Research Institute, Western Region Climate Center, Reno, NV; http://www.wrcc.dri.edu). Dominant shrubs included mountain mahogany (Cercocarpus montanus), creeping barberry (Mahonia repens), and antelope brush (Purshia tridentata), whereas prevalent trees were ponderosa pine (Pinus ponderosa), pinyon pine (P. edulis), alligator juniper (Juniperus deppeana), oaks (Quercus spp.), and honey mesquite (Prosopis glandulosa). Approximately 200-300 head of AngusHereford cross-bred cattle grazed year-round during the study.

We monitored foals with ear-tag transmitters in the central portion of the Dorsal Galega (CDG) mountain range $\left(43^{\circ} \mathrm{N}\right.$, $7^{\circ} \mathrm{W}$ ) in Galicia, northwestern Spain, in 2 separate areas that totaled 454 ha, but that were located $1.6 \mathrm{~km}$ apart. Elevation ranged from $570 \mathrm{~m}$ to $803 \mathrm{~m}$ above mean sea level, topography was variable, and vegetation type ranged from timbered areas to meadows. Annual precipitation was between $130 \mathrm{~cm}$ and $190 \mathrm{~cm}$, and mean annual temperature was $11^{\circ} \mathrm{C}$, with extremes of $-8^{\circ} \mathrm{C}$ and $36^{\circ} \mathrm{C}$ (Carballeira et al. 1983, Martínez et al. 1999). Shrub vegetation on the CDG included gorse (Ulex europaeus), broom (Cytisus striatus, C. scoparius), bramble (Rubus ulmifolius), and heather (Erica spp.). Prevalent trees were Monterey pine (Pinus radiata), English oak (Quercus robur), birch (Betula celtiber- $i c a$ ), and eucalyptus (Eucalyptus spp.). The adult population of Galician feral horses (Iglesia 1973) monitored in the CDG during the study included 4-8 adult males and 53-59 adult females.

\section{METHODS}

\section{Data Collection}

During 2005 and 2006, we affixed 256 ear-tag transmitters with mortality sensors (model M3610; Advanced Telemetry Systems, Isanti, MN; Fig. 1A) to calves on the EE (transmitters were crystal-controlled 2-stage transmitter; mass = $22 \mathrm{~g}$; http://www.atstrack.com/ats/seriesPDF/M3600.PDF, accessed 25 Jun 2011). We attached these transmitters using cattle ear-tag pliers to the base of the inner side of the left outer ear, usually within 1-2 weeks of birth, and monitored transmitter signals daily from March through October and approximately once per week during winter months. We also marked cattle with uniquely numbered ear tags attached to the right ear (Fig. 1A) so they could be identified visually.

We determined transmitter retention on the EE by recovering any transmitter sending a mortality signal and determining whether it had detached from the ear (i.e., no sign of a carcass). When the exact date of detachment was unknown, we designated retention loss as the middle day of the period between checks (Mayfield 1961, 1975). Due to the size of our
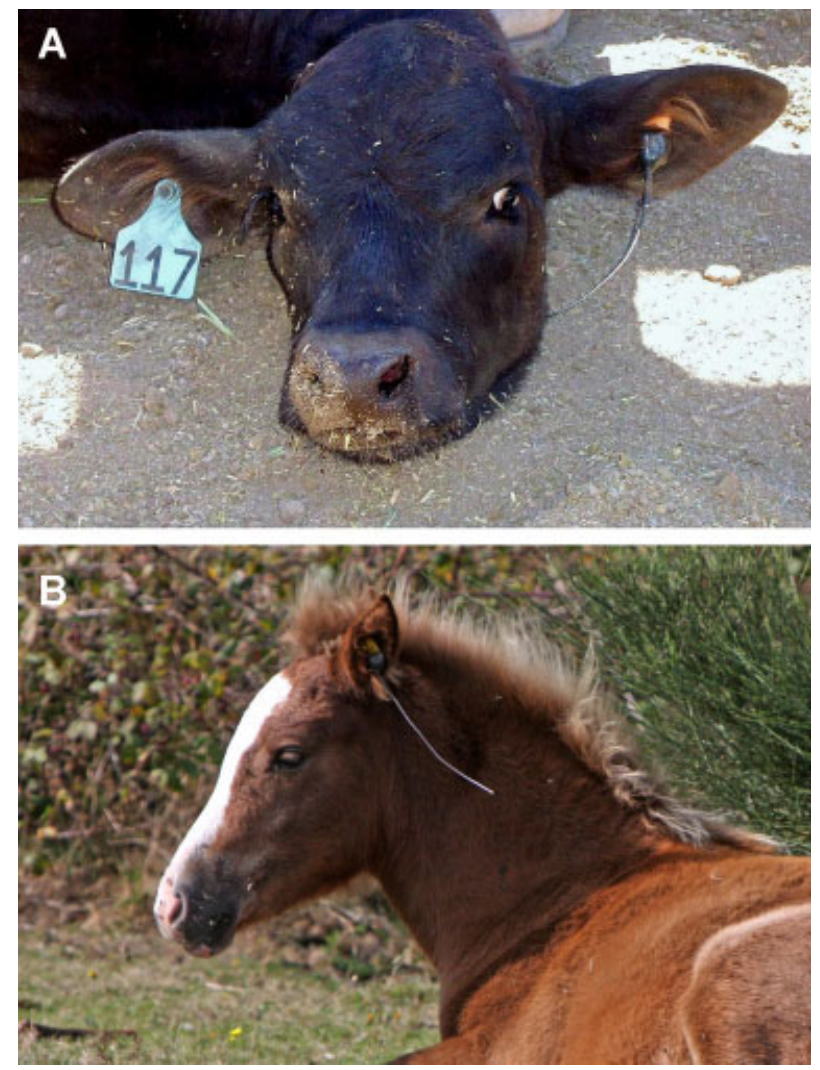

Figure 1. Examples of ear-tag transmitters attached to study animals, with (A) model M3610 (Advanced Telemetry Systems, Isanti, MN) attached to the interior of the left outer ear of a calf in East Eagle, Arizona, USA (20052006), and (B) model M3430 (Advanced Telemetry Systems) attached to the interior of the left outer ear of a foal in the central portion of Dorsal Galega, northwestern Spain (2007-2009). 
study area, we were unable to recover 6 transmitters, but were able to determine that these transmitters lost retention by inspecting animals at roundup (every 3-6 months). Transmitters that lost retention and were not recovered $(n=6)$ were not used for integrity analyses because the condition of transmitters prior to falling off was unknown (i.e., the transmitter could have lost integrity prior to falling off). Often, ear-tag radios stopped transmitting because the antenna was severed from the transmitter, but we were unable to determine this fact until the next roundup. For this reason, we designated transmitter integrity loss as the midpoint of the interval between the last time a signal was heard and examination at roundup (Mayfield 1961, 1975).

From 2007 to 2009, we attached 14 ear-tag transmitters equipped with mortality sensors (model M3430; Advanced Telemetry Systems) to 32 foals (Fig. 1B) on the CDG (transmitters were crystal-controlled 2-stage transmitter; mass = 23 g; http://www.atstrack.com/ats/seriesPDF/M3400.PDF, accessed 25 Jun 2011). Transmitters we recovered intact were affixed to new foals and considered separate transmitters for retention analyses, but not integrity analyses. All of these transmitters lost integrity whether used singularly (4 of 4) or on multiple animals (11 of 11). We attached 18 transmitters to the inside of the outer ear (Fig. 1B) and 14 to the outside of the outer ear. We attached transmitters during roundups, with the age of foals ranging from 13 days to 185 days ( $75 \%$ within 3 months of birth). We individually identified foals by their physical characteristics.

We visually inspected foals on the CDG for broken, missing, and operable transmitters every 2 weeks. We checked the radio signal of transmitters daily from a permanent installation consisting of a fixed antenna and a receiver. For transmitters that fell off in areas not covered by the fixed antenna, we assigned the loss date as the middle day of the unknown period (Mayfield 1961, 1975). Visual inspection allowed us to observe when the transmitters lost integrity in 15-day periods, so we assigned integrity loss as the middle day between monitoring periods (Mayfield 1961, 1975) unless daily checks of the radio signal allowed us to estimate the exact failure date.

\section{Data Analyses}

We calculated integrity by taking the number of transmitters that lost integrity divided by the number of transmitters attached, and retention as the number of tags that fell off divided by the number of tags attached. We used KaplanMeier time-to-failure analysis (Kleinbaum and Klein 2005) to predict a time of complete retention and integrity loss for all transmitters. For transmitters used several times, we calculated integrity by adding the periods when the transmitters were affixed to different foals until they lost integrity; we did not include the periods when transmitters were not affixed to foals. We tested for differences between integrity and retention (proportion of transmitters that lost retention or integrity) between sites and/or species, as well as for differences between retention for transmitters placed on the inside and outside of foals' ears at the CDG using a 2-tailed Fisher's exact test (Zar 2009) at a significance level of
$P<0.10$. All statistical analyses were conducted in JMP 8.1 (SAS Institute, Cary, NC).

\section{RESULTS}

Twenty-four percent (60 of 250) and 100\% (14 of 14) of transmitters lost integrity at the EE and CDG, respectively $(P \leq 0.001)$. Mean time to failure at the $\mathrm{EE}$ was 121 days $(\mathrm{SD}=37.7)$, while transmitters at the $\mathrm{CDG}$, on average, failed at 71 days $(S D=45.5)$. Mean time to failure for transmitters that lost integrity pooled across study sites was 111 days $(\mathrm{SD}=44.7$; Fig. $2 \mathrm{~A}$ ), whereas predicted loss of integrity for all transmitters was 168 days $(\mathrm{SE}=$ 4.3, $N=264)$.

At the EE and CDG, 3.5\% (9 of 256) and 37.5\% (12 of 32) of transmitters lost retention, respectively $(P \leq 0.001)$. The mean drop time was 234 days $(\mathrm{SD}=139.0)$ and 139 days $(\mathrm{SD}=155.2)$ at the $\mathrm{EE}$ and $\mathrm{CDG}$, respectively. The mean drop time across both study sites was 180 days $(\mathrm{SD}=152.6$; Fig. 2B). The failure analyses predicted that $100 \%$ of transmitters would lose retention at 420 days $(\mathrm{SE}=24.5$, $N=288$ ). Transmitters that maintained retention at the EE were last examined affixed to animals at an average of $147(\mathrm{SD}=83.6)$ days $($ range $=6-430)$. Transmitters that
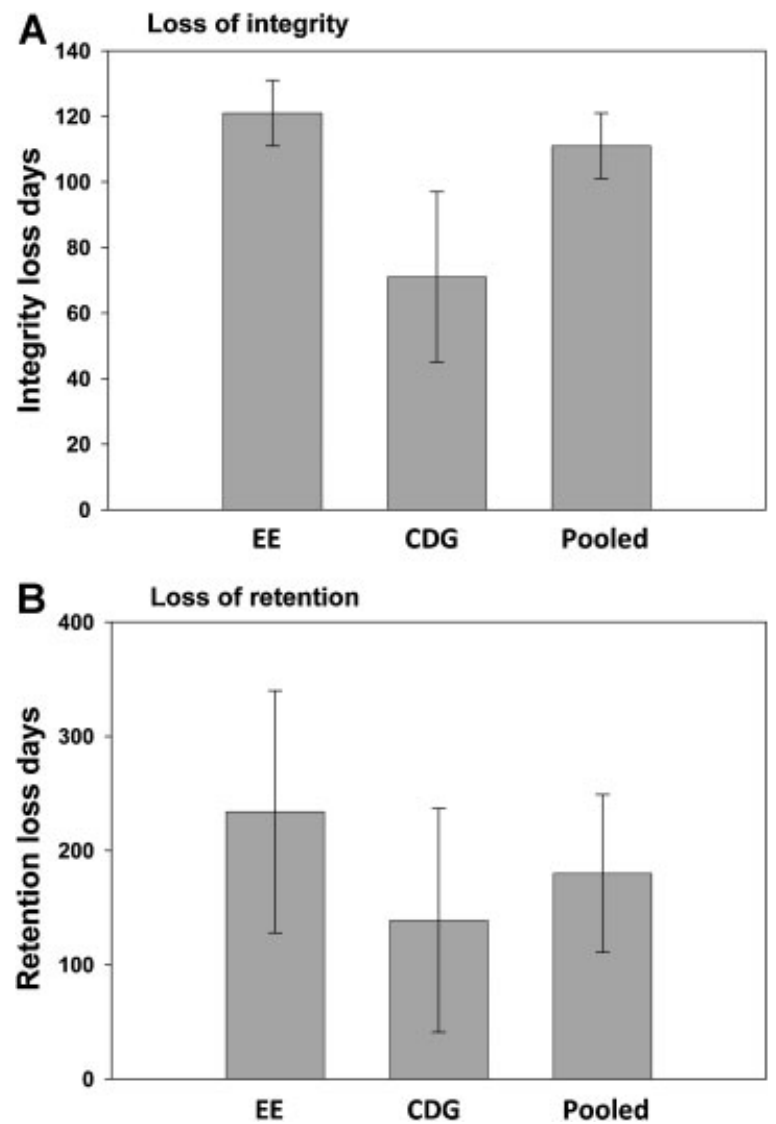

Figure 2. (A) Number of days $(\bar{x} \pm 95 \%$ CI $)$ until ear-tag transmitters attached to study animals during 2005-2009 lost integrity, and (B) number of days $(\bar{x} \pm 95 \% \mathrm{CI})$ until transmitters lost retention at East Eagle, Arizona (EE), and the central portion of Dorsal Galega, northwestern Spain (CDG), and across study sites (Pooled). Number of transmitters that lost integrity and retention at the EE, CDG, and Pooled were 60,14, and 74, and 9, 12, and 21 , respectively. 
maintained retention at the CDG were last examined affixed to animals at a mean of $119(\mathrm{SD}=135)$ days (range $=3-$ 426). Fifty-seven percent ( 8 of 14) of transmitters placed in the exterior of foals' ears lost retention, but only $22 \%$ ( 4 of 18 ) of those placed in the interior of the ear lost retention $(P=0.068)$.

\section{DISCUSSION}

We documented high rates of integrity loss for ear-tag transmitters, differences in transmitter integrity by study site and/or species, differences in time to integrity loss between sites, and that overall time to integrity loss was short. For example, $24 \%$ of transmitters failed on calves at the EE, $100 \%$ of transmitters failed on foals at the CDG, and the mean times to integrity loss at the EE and CDG were only 121 days and 71days, respectively (Fig. 2A). Typically, loss of integrity occurred when antennas became frayed or detached from the transmitter. This problem could be addressed by strengthening the portion of the transmitter where the antennae attaches or by increasing the diameter of the antennae. We modified 3 of the transmitters used at the CDG by having the manufacturer reinforce antennae with a plastic coating near the end of the study, an action that appeared to increase integrity. We did not include these data in our analyses due to small sample size. More work is needed to address this problem.

Differences in transmitter integrity rates and time to integrity failure between sites and/or species could have been due to differences between the 2 transmitter models or differences in how roughly calves versus foals treated the transmitters. In other studies, failure rates for ear-tag transmitters varied from $17 \%$ for calves in Idaho, USA (J. Oakleaf, United States Fish and Wildlife Service, personal communication) to as high as $56 \%$ for wild boar in central Florida, USA (Arrington et al. 1999). Arrington et al. (1999) maintained that the high failure rates for ear-tag transmitters in their study occurred because wild boars routinely engaged in rooting behavior that could easily damage transmitters. Because we have no reason to expect that foals treated transmitters more roughly than calves, we suspect that differences in how the 2 transmitter models were manufactured probably accounted for the disparity in integrity loss rate and time to integrity loss between study sites and/or species. If one were to use both models of transmitters attached the same way to the ears of both calves and foals simultaneously, these relationships could be elucidated.

We also documented marked differences in retention rates for ear-tag transmitters by study site and/or species, and that time to transmitter loss was short, but did not differ between study site and/or species. Only $3.5 \%$ of transmitters lost retention at the $\mathrm{EE}$, whereas $37.5 \%$ were lost at the $\mathrm{CDG}$, and the mean times to transmitter loss at the EE and CDG were 234 days and 139 days, respectively (Fig. 2B). Our results from the EE were similar to those reported for ear-tag transmitters on elk $(0.5 \%$ and $5.0 \%$, respectively; Smith et al. 2006, Barber-Meyer et al. 2008). Conversely, the rate of retention loss for foals on the CDG was the highest reported. Both transmitter models used during our study were similar in mass ( $22 \mathrm{~g}$ vs. $23 \mathrm{~g}$ ), but the plastic backing used to affix the transmitters to the ear was nearly twice as wide for the M3610 used at the EE as that for the M3430 used on the CDG (45 mm vs. $25 \mathrm{~mm}$, respectively). We expect the wider backing was less likely to break or tear out of the ear. It also is possible that the thicker ear cartilage of calves versus foals (R. T. Skirpstunas, Utah State University, personal communication) may have contributed to observed differences in transmitter retention rates. Regardless, our results clearly demonstrate the superiority of placing the transmitter on the inside rather than the outside of the ear.

To our knowledge, our study is the first reporting timing of integrity and retention loss for ear-tag radiotransmitters. Our data revealed a trend of integrity loss occurring at a higher frequency and over a shorter time frame than retention loss. This is important because integrity issues can likely be improved upon by manufactures making transmitters more robust while not significantly increasing transmitter mass. Clearly, loss of radiotags also can influence any study or monitoring plan. For this reason, practitioners should record the extent and timing of integrity and retention loss so that we can better understand the effectiveness of ear-tag transmitters under various environmental conditions and across an array of species. Future studies that affix transmitters to different species in the same area, or attach various transmitter models to the same species, will enhance our knowledge of the effectiveness of ear-tag transmitters.

\section{MANAGEMENT IMPLICATIONS}

Our results suggest that wildlife managers and researchers using radiotag transmitters should be wary regarding how well these products perform. Specifically, their effectiveness may vary widely by transmitter model, animal species, and the environment where they are deployed. Researchers and managers who deploy transmitters similar to the models we used should expect integrity loss to occur on a greater number of transmitters, and to occur more rapidly, than retention loss. Reinforcing transmitter antennae should improve integrity, whereas increasing the width of transmitter backing should increase retention. Ear-tag transmitters should be placed in the interior versus the exterior side of the outer ear for species similar to those we evaluated. Finally, we encourage researchers and managers to report rates and timing of retention and integrity loss when using ear-tag radiotransmitters so that more reliable knowledge can be generated regarding factors that influence integrity and retention of ear-tag transmitters.

\section{ACKNOWLEDGMENTS}

L. G. Fornara, S. M. Smith, and J. M. Timmer were invaluable field assistants. C. D. Carrillo and T. B. Veenendaal provided essential logistical and intellectual support. J. B. Juarez provided essential assistance with attachment of ear-tag radiotransmitters to calves. Mr. and Mrs. G. C. Ely provided uninterrupted access to cattle. We are grateful to L. García for regularly monitoring the CDG transmitters during the study. A. Abad, Á. González, 
E. Vidal, and J. Casal helped capture and tag foals. We thank the 2 anonymous reviewers and Associate Editor M. J. Peterson for providing detailed critiques of our manuscript.

\section{LITERATURE CITED}

Aanes, R., and R. Andersen. 1996. The effects of sex, time of birth, and habitat on the vulnerability of roe deer fawns to red fox predation. Canadian Journal of Zoology 74:1857-1865.

Arjo, W. M., R. E. Joos, C. O. Kochanny, J. L. Harper, D. L. Nolte, and D. L. Bergman. 2008. Assessment of transmitter models to monitor beaver Castor canadensis and C. fiber populations. Wildlife Biology 14:309317.

Arrington, D. A., L. A. Toth, and J. W. Koebel. 1999. Effect of rooting by feral hogs Sus scrofa L. on the structure of a floodplain vegetative assemblage. Wetlands 19:535-544.

Barber-Meyer, S. M., L. D. Mech, and P. J. White. 2008. Elk calf survival and mortality following wolf restoration to Yellowstone National Park. Wildlife Monographs 169.

Breck, S. W., B. M. Kluever, M. Panasci, J. Oakleaf, T. Johnson, W. Ballard, L. Howery, and D. L. Bergman. 2011. Domestic calf mortality and producer detection rates in the Mexican wolf recovery area: implications for livestock management and carnivore compensation schemes. Biological Conservation 144:930-936.

Carballeira, A., C. Devesa, R. Retuerto, E. Santillán, and F. Ucieda. 1983. Bioclimatología de Galicia. Fundación Pedro Barrié de la Maza, Conde de Fenosa, La Coruña, Spain. http://books.google.es/books/about/ Bioclimatolog\%C3\%ADa_de_Galicia.html?id=OFLvcQAACAAJ\&redir_ esc $=\mathrm{y}$

Decker, T. A., W. H. Healy, and S. A. Williams. 1992. Survival of white-tailed deer fawns in western Massachusetts. Northeast Wildlife 49:28-35.

DeVivo, M. T., W. O. Cottrell, J. M. DeBerti, J. E. Duchamp, L. M. Hefferman, J. D. Kougler, and J. L. Larkin. 2011. Survival and cause specific mortality of elk Cervus canadensis calves in a predator rich environment. Wildlife Biology 17:156-165.

Diefenbach, D. R., C. O. Kochanny, J. K. Vreeland, and B. D. Wallingford. 2003. Evaluation of an expandable, breakaway radiocollar for white-tailed deer fawns. Wildlife Society Bulletin 31:756-761.

Fisher, C., H. Gourdin, and M. Obermann. 2004. Spatial behaviour of the wild boar in Geneva, Switzerland: testing the methods and first results. Galemys 16:149-155.

Gaillard, J. M., D. Delorme, J.-M. Boutin, G. Van Laere, B. Boisaubert, and R. Pradel. 1993. Roe deer survival patterns: a comparative analysis of contrasting populations. Journal of Animal Ecology 62:778-791.

Garrott, R. A., R. M. Bartmann, and G. C. White. 1985. Comparison of radio-transmitter packages relative to deer fawn mortality. Journal of Wildlife Management 49:758-759.

Iglesia, P. 1973. Los caballos gallegos explotados en régimen de libertad o caballos salvajes de Galicia. Facultad de Veterinaria, Universidad Complutense de Madrid, Madrid, Spain.
Kissling, W. D., N. Fernandez, and J. M. Paruelo. 2009. Spatial risk assessment of livestock exposure to pumas in Patagonia, Argentina. Ecography 32:807-817.

Kleinbaum, A. F., and M. Klein. 2005. Survival analysis: a self-learning text. Springer, New York, New York, USA.

Kluever, B. M., S. W. Breck, L. D. Howery, P. R. Krausman, and D. L. Bergman. 2008. Vigilance in cattle: the influence of predation, social interactions, and environmental factors. Rangeland Ecology and Management 61:321-328.

Lancia, R. A. 1979. Year-long activity patterns of radio-marked beavers (Castor canadensis). Dissertation, University of Massachusetts, Amherst, USA.

Long, R. A., A. F. O’Connell, and D. J. Harrison. 1998. Mortality and survival of white-tailed deer Odocoileus virginianus fawns on a North Atlantic coastal island. Wildlife Biology 4:237-247.

Martínez, A., F. Castillo, A. Pérez, M. Valcárcel, and R. Blanco. 1999. Atlas climático de Galicia. Xunta de Galicia, Santiago de Compostela, Galicia, Spain.

Mayfield, H. 1961. Nesting success calculated from exposure. Wilson Bulletin 73:255-261.

Mayfield, H. 1975. Suggestions for calculating nest success. Wildlife Society Bulletin 87:456-466.

Millspaugh J. J. and J. M. Marzluff, editors. 2001. Radio tracking and animal populations. Academic Press, San Diego, California, USA.

Morrison, M. L., W. M. Block, M. D. Strickland, B. A. Collier, and M. J. Peterson. 2008. Wildlife study design. Second edition. Springer, New York, New York, USA.

Oakleaf, J. K., C. Mack, and D. L. Murray. 2003. Effects of wolves on livestock calf survival and movements in central Idaho. Journal of Wildlife Management 67:299-306.

Raganella-Pelliccioni, E., L. Boitani, and S. Toso. 2006. Ecological correlates of roe deer fawn survival in a sub-Mediterranean population. Canadian Journal of Zoology 84:1505-1512.

Smith, B. L., and S. H. Anderson. 1998. Juvenile survival and population regulation of the Jackson elk herd. Journal of Wildlife Management 62:1036-1045.

Smith, B. L., W. P. Burger, and F. J. Singer. 1998. An expandable radio collar for elk calves. Wildlife Society Bulletin 26:113-117.

Smith, B. L., E. S. Williams, K. C. McFarland, T. L. McDonald, G. Wang, and T. D. Moore. 2006. Neonatal mortality of elk in Wyoming: environmental, population, and predator effects. U.S. Department of Interior, Fish and Wildlife Service Biological Technical Publication BTP-R60072006, Washington, D.C., USA.

Wheatley, M. 1997. A new surgical technique for implanting radio transmitters in beavers, Castor canadensis. Canadian Field-Naturalist 111:601606.

Zar, J. H. 2009. Biostatistical analysis. Fifth edition. Prentice Hall, Upper Saddle River, New Jersey, USA.

Associate Editor: Peterson. 